Canadian

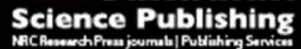

Canadian Journal of Physiology and Pharmacology Revue canadienne de physiologie et pharmacologie

\title{
Accelerated gastric ulcer healing in thyroxine-treated rats; roles of gastric acid, mucus and inflammatory response
}

\begin{tabular}{|c|c|}
\hline Journal: & Canadian Journal of Physiology and Pharmacology \\
\hline Manuscript ID & cjpp-2017-0399.R1 \\
\hline Manuscript Type: & Article \\
\hline Date Submitted by the Author: & 06-Oct-2017 \\
\hline Complete List of Authors: & $\begin{array}{l}\text { Adeniyi, Olasupo; Benue State University College of Health Science, } \\
\text { Physiology } \\
\text { Emikpe, Benjamin; University of Ibadan Faculty of Veterinary Medicine, } \\
\text { Vterenary Pathology } \\
\text { OLALEYE, SAMUEL; University of Ibadan, Faculty of Basic Medical Sciences, } \\
\text { Physiology; }\end{array}$ \\
\hline Keyword: & thyroxine, ulcer, healing, acid, mucus \\
\hline $\begin{array}{r}\text { Is the invited manuscript for } \\
\text { consideration in a Special } \\
\text { Issue?: }\end{array}$ & N/A \\
\hline
\end{tabular}


Accelerated gastric ulcer healing in thyroxine-treated rats; roles of gastric acid, mucus and inflammatory response

By

Olasupo S. Adeniyi ${ }^{1}$, Benjamin O. Emikpe ${ }^{2}$, Samuel B. Olaleye ${ }^{3}$

${ }^{1}$ Department of Physiology, Faculty of Basic and Allied Medical Sciences, Benue State University, Makurdi, Benue State, Post Code 972221, Nigeria; supoadeniyi@yahoo.com

${ }^{2}$ Department of Veterinary Pathology, Faculty of Veterinary Medicine, University of Ibadan, Ibadan, Oyo State, Post code 200284, Nigeria; banabis2001@yahoo.com

${ }^{3}$ Laboratory for Gastrointestinal Secretion and Inflammation Research, Department of Physiology, College of Medicine, University of Ibadan, Ibadan, Oyo State, Post code 200284, Nigeria; sbolaleye@yahoo.com

\section{Corresponding Author:}

Dr. Olasupo S. Adeniyi, Faculty of Basic and Allied Medical Sciences, College of Health Sciences, PMB 102119, Benue State University, Makurdi, Benue State, Nigeria.

E-mail address: supoadeniyi@yahoo.com

Mobile number: $+2348051980450,+2348038629046$ 


\begin{abstract}
The roles of gastric acid, mucus and inflammation on the pro ulcer-healing effect of thyroid hormone were investigated. Male Wistar rats were randomly divided into 4 groups: control, thyroidectomised, thyroidectomised with thyroxine treatment $(100 \mu \mathrm{g} / \mathrm{kg} / \mathrm{day})$ and sham operated animals treated with thyroxine. Thirty-five days after thyroidectomy, sham surgery or thyroxine treatment, ulcer was experimentally induced. Healing was assessed 3, 7 and 10 days post ulceration by measurement of ulcer area, gastric mucus and acid secretion, and neutrophil lymphocyte ratio (NLR) as an index of inflammation. By day 10, ulcer area had reduced in all groups. Recovery was significantly greater $(P<0.05)$ in thyroxine treated rats $(78.5 \pm 1.6 \%$ reduction in ulcer area) than in controls $(72.3 \pm 1.2 \%$ reduction), or thyroidectomised rats $(63.3 \pm 1.9 \%$ reduction $)$. Thyroxine treated animals also had the highest reduction in NLR $(65.0 \pm 2.5 \%)$. Mucus secretion was significantly lower $(P<0.05)$ in thyroidectomised rats by days 3 and 7 . Furthermore by day 10, the concentration of basal acid reduced by $77.4 \pm 2.6 \%$ in thyroxine treated; $65.0 \pm 0.0 \%$ in control and $51.5 \pm 3.3 \%$ in thyroidectomised rats. We conclude that, thyroxine accelerates gastric ulcer healing by altering mucus and acid secretion and reducing NLR.
\end{abstract}

Keywords: thyroxine, ulcer, healing, acid, mucus, inflammation 


\section{Introduction}

Gastric ulcer healing involves filling the mucosal defect with connective tissues; epithelial cell proliferation, migration and differentiation; gland reconstruction and angiogenesis. These activities are controlled by several factors including: nitric oxide, fibroblast growth factor, epidermal growth factor, hepatocyte growth factor, insulin-like growth factor 1, trefoil factors, prostaglandins, vascular endothelial growth factor, angiopoietins and several cytokines that act in a spatially and temporally coordinated manner (Khoder et al. 2016; Tarnawski et al. 2012; Nguyen et al. 2007; Ma and Wallace 2000).

Reduction in gastric acid secretion is a major target of physicians when treating gastric ulcers and treatment with drugs that achieve this, such as proton pump inhibitors (omeprazole, lanzoprazole) and H2 blockers (cimetidine, ranitidine), accelerate the healing of ulcers (Strand et al. 2017). Gastric mucus secretion not only plays a defensive role in preventing aggressive factors from injuring the stomach, it also has roles in the healing of ulceration, acting as an antioxidant, providing a suitable gastric $\mathrm{pH}$ environment for epithelial restitution and enhancing the binding of growth factors to their receptors on the stomach (Rowland et al. 2013; Yandrapu and Sarosiek 2015).

Neutrophil to lymphocyte ratio (NLR) is an essential marker of inflammation that is useful as a prognostic index for gastric cancer (Soylu et al. 2016; Hu et al. 2015). A study by Tanrikulu et al. (2015) revealed that NLRs were higher in patients with peptic ulcer perforation compared with patients having non-complicated peptic ulcer and those presenting with nonspecific abdominal pain (as a control). Jafarzadeh et al. (2013) reported that NLR was significantly higher among Helicobacter pylori (H. pylori) infected patients with peptic ulcer than in healthy $H$. pylori negative subjects. Further, NLR was significantly higher 
among Helicobacter pylori-infected asymptomatic subjects than in healthy patients. These suggest that there might be a relationship between NLR and ulcer disease and NLR might be a useful tool in assessing ulcer severity and treatment success.

Previous work showed that thyroid hormones facilitate gastric ulcer healing by accelerating the inflammatory and proliferative phases of healing, reducing lipid peroxidation, modulating apoptosis and haematological parameters (Olaleye et al. 2013; Adeniyi et al. 2014), but there are still several other parameters that we do not have information about during healing of gastric ulcer in altered thyroid states. Gastric acid secretion, mucus secretion and blood cells have been found to affect ulcer healing, therefore, this research aimed to further investigate the mechanisms by which thyroid hormones affect ulcer healing by measuring acid secretion, mucus secretion and NLR during healing in rats. 


\section{Materials and methods}

A total of 120 male albino Wistar rats $(160-200 \mathrm{~g})$ were obtained from the Animal House of the College of Medicine, University of Ibadan, Nigeria. They were randomly divided into four weight-matched groups, kept in wire meshed cages and fed with a standard diet of commercial rat chow and tap water ad libitum. Animal care and handling was in line with the guidelines of the Institutional Research and Ethics Committee, which is in accordance with the Guide for the Care and Use of Laboratory Animals (1996, published by National Academy Press, 2101 Constitution Ave. NW, Washington, DC 20055, USA).

\section{Surgical procedures}

Thyroidectomy sham operation

The animals were anaesthetised using $50 \mathrm{mg} / \mathrm{kg}$ thiopentone sodium injected intraperitoneally (i.p). A midline incision was made on the skin in the neck region and the thyroid gland was exposed, but not removed. The cut was sutured back, cleaned with procain penicillin. The animals were allowed to recover, returned to their cages and fed with standard diet and tap water.

\section{Thyroidectomy}

For thyroidectomy, rats were anaesthetized using $50 \mathrm{mg} / \mathrm{kg}$ thiopentone sodium (i.p), a midline incision was made in the neck region, the skin was bilaterally retracted, the fascia and the muscle covering the thyroid gland were carefully removed, and the thyroid gland was then extirpated. Care was taken so that the parathyroid glands were not removed (the parathyroid gland could be visibly seen as a whitish coloured structure on the posterior wall of the thyroid glands and could be easily detached from the thyroid gland together with the 
connective tissue connected to it). The incision was sutured back, cleaned with procain penicillin and the animals were returned to standard diet and tap water.

\section{Animal grouping and treatment}

Group 1: sham operated euthyroid animals with no treatment.

Group 2: untreated thyroidectomised animals.

Group 3: thyroidectomised rats treated with $100 \mu \mathrm{g} / \mathrm{kg} /$ day levothyroxine sodiumorally for 35 days (Olaleye et al. 2013)

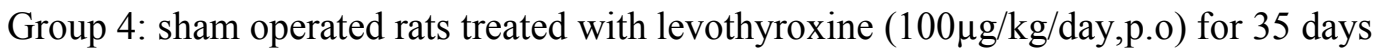

Ulcer induction

After the 35 days of drug treatment and thyroid gland surgery, gastric ulcers were induced using the method of Wang et al. (1990) with some modifications. The animals were deprived of food, but had free access to water for $18 \mathrm{~h}$ before ulcer induction. Rats were anaesthetized using $50 \mathrm{mg} / \mathrm{kg}$ thiopentone sodium (i.p), laparotomy was performed, the stomach was exposed, an area of the distal antrum isolated with a clamp (using round forceps - ID 9mm) and acute gastric ulcer was induced by injection of $50 \% \mathrm{v} / \mathrm{v}$ acetic acid $(0.04 \mathrm{~mL})$ into the clamped portion (Okabe et al. 2005). After 60 seconds, the acetic acid was withdrawn back,the serosa of the stomach was gently cleaned with normal saline and the stomach returned into the abdominal cavity. The abdomen was sutured back and the animals were placed in their cages after recovery with free access to food and water.

Measurement of ulcer healing was carried out in 2 phases:

i. $\quad 60$ rats were used for the first phase, divided into four groups of 15 animals and treated as described above (Animal grouping and treatment). At each of days 3, 7 
and 10, five rats of each group were selected at random. They were first anaesthetized and blood was obtained for blood cell count. They were then immediately sacrificed and the stomachs removed for measurement of ulcer area and measurement of mucus secretion.

ii. Another set of 60 rats were used for the $2^{\text {nd }}$ phase of the experiment. They were treated and grouped as above, but were used for gastric acid secretion studies only.

\section{Calculation of neutrophil-lymphocyte ratio and measurement of ulcer area}

Five animals from each group were randomly selected at days 3, 7 and 10 post ulcer induction and blood was collected from each rat via the orbital artery for differential white blood cell counts (Lewis et al. 2006). Neutrophil-lymphocyte ratio was calculated by dividing the neutrophil count by the lymphocyte count. The rats were then sacrificed by cervical dislocation, the abdomen was cut open; the stomach was brought out, opened along the greater curvature, rinsed with normal saline and then spread out. Transparent paper was placed over the stomach and the ulcer area was traced out by a researcher, who was blind to the treatments. Ulcer area was converted to $\mathrm{mm}^{2}$ using $1 \mathrm{~mm}$ by $1 \mathrm{~mm}$ paper grid. The percentage area of ulcer healed was calculated as:

Percentage of area healed on day $7=$ Area of ulcer on day $3-$ area of ulcer on day $7 \times 100$

Area of ulcer on day 3

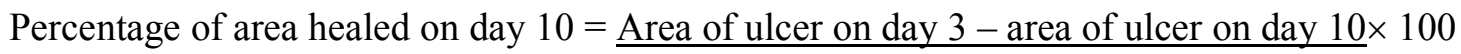

Area of ulcer on day 3 


\section{Measurement of mucus secretion}

Measurement of adherent gastric mucus secretion was carried out using the method described by Corne et al. (1974). The animals were sacrificed by cervical dislocation, the stomachs were removed, opened along the greater curvature, washed with normal saline and rapidly transferred to soaked in $0.1 \%$ Alcian blue dissolved in buffer solution containing $0.1 \mathrm{M}$ sucrose and $0.05 \mathrm{M}$ sodium acetate ( $\mathrm{pH}$ adjusted to 5.8 with hydrochloric acid) for 2 hours. After washing the stomach twice in $0.25 \mathrm{M}$ sucrose at $15 \mathrm{~min}$ and $45 \mathrm{~min}$, the dye complexed with mucus was eluted by immersion in $10 \mathrm{~mL}$ aliquots of $0.5 \mathrm{M} \mathrm{MgCl}_{2}$ for 2 hours. The resulting blue solution was shaken with equal volumes of diethyl ether and the optical density of the aqueous phase was measured at $605 \mathrm{~nm}$ using a spectrophotometer.

Using a standard curve, the absorbance of each solution was used to calculate the dye concentration and therefore the weight of dye taken up (expressed in $\mathrm{mg}$ ). The weight of the dye was then expressed over the weight of the stomach.

\section{Measurement of Basal and Histamine Stimulated Gastric Acid Secretion}

Measurement of the acidity of the gastric secretion was carried out using the continuous perfusion method (Ghosh and Schild 1958) with some modifications (Olaleye et al. 2012). Rats were anaesthetised using $25 \%$ urethane, injected intraperitoneally at a dose of $0.6 \mathrm{~mL} / 100 \mathrm{~g}$ body weight. A blunt dissection was done in the neck region to expose the trachea. After separating the trachea from the esophagus, a small cut was made in the upper part of the trachea and a $2.5 \mathrm{~cm}$ long polythene size " 3 " cannula was inserted. This method avoids respiratory difficulty by bye-passing the nasal passage to the larynx, and also allows aspiration of any fluid that accumulates in the trachea during the rest of the procedure. In order to prevent drying up of the exposed tissue, saline soaked cotton wool was placed over 
the dissected area. Then another size "3" polythene cannula from a Lagendorff apparatus was passed into the esophagus to reach the stomach for perfusion.

The linear alba was cleared of hair, a midline incision was made through the abdominal wall, the stomach was brought out and a small cut was made about an inch distal to the pyloroduodenal junction. The stomach was washed of all food debris using a Langendoff apparatus, with perfusion fluid maintained at $37^{\circ} \mathrm{C}$. With the perfusion fluid still running, the early part of the duodenum was cannulated and the stomach was packed back into the peritoneum. The muscle was sutured back before the skin and it was ensured that the perfusion fluid was running out of the stomach. After collecting consistent basal output, $0.5 \mathrm{mg} / \mathrm{kg}$ histamine acid phosphate was injected into each animal intramuscularly.

\section{Collection of Samples}

The rate of flow of the perfusion fluid was adjusted such that $10 \mathrm{~mL}$ of effluent (which contains gastric juice from the stomach) was collected at 15 minutes intervals for 3 hours. The first four effluents were collected to establish a consistent basal output.

\section{Titration Procedure}

After each sample collection, $5 \mathrm{~mL}$ from the $10 \mathrm{~mL}$ collected was measured into a conical flask, two drops of phenolphthalein reagent was added and titrated against $0.0025 \mathrm{M} \mathrm{NaOH}$ until the first appearance of a pink colour. At this point, the titration was stopped and the end point recorded. 


\section{Statistical Analysis}

Results are expressed as mean \pm SEM. Statistical difference between the different groups was evaluated using ANOVA with Bonferroni post hoc test. The values were considered significant when $P<0.05$. Data were analyzed using SPSS version 18 software (SPSS Science, Chicago, IL, USA). 


\section{Results}

\section{Measurement of ulcer area}

At day 3 after ulcer induction, the gastric ulcer area in control rats was $7.6 \pm 0.18 \mathrm{~mm}^{2}$. This was not significantly different from that in thyroidectomised and thyroidectomised $+\mathrm{T} 4$ groups, but was significantly greater than ulcer area in thyroxine treated rats $\left(5.4 \pm 0.24 \mathrm{~mm}^{2}\right)$. Ulcer areas in all the groups of animals were significantly reduced by days 7 and 10 (Table 1). Furthermore, ulcer area in thyroxine treated rats was significantly $(\mathrm{p}<0.05)$ lower than that measured in control and thyroidectomised at days 7 and 10. Figure 1, shows that by day 10, healing was most rapid in thyroxine treated rats. The area of ulcer in this group was significantly $(P<0.05)$ reduced, by $78.5 \pm 1.6 \%$ when compared to day 3 in the same group. In comparison, controls experienced a $72.3 \pm 1.2 \%$ reduction in ulcer area, while the reduction in area of mucosa eroded was significantly $(P<0.05)$ less in thyroidectomised animals $(63.3 \pm 1.9 \%)$. Thyroidectomy $+\mathrm{T}_{4}$ also exhibited significantly $(P<0.05)$ reduced ulcer area eroded on day 10, by $77.5 \pm 1.9 \%$ as shown in Figure 1.

\section{Neutrophil lymphocyte ratio after ulcer induction}

Table 2 shows that the neutrophil lymphocyte ratio $(\mathrm{NLR})$ was significantly $(P<0.05)$ lower in control animals by day 3 , when compared with the other groups. Neutrophil lymphocyte ratio significantly $(P<0.05)$ reduced in all groups of animals by day 10 after ulcer induction. However, Figure 2 shows that by day 10, the reduction in NLR in thyroxine treated rats $(65.0$ $\pm 2.5 \%)$ was significantly higher than that in controls $(28.3 \pm 2.8 \%)$, thyroxine replacement therapy $(46.0 \pm 3.6 \%)$ and thyroidectomised rats $(20.1 \pm 1.7 \%)$. 


\section{Measurement of mucus secretion}

Mucus secretion was significantly lower $(P<0.05)$ in thyroidectomised rats, when compared with control by day 3 , but there was no significant $(P>0.05)$ difference in secretion between control and thyroxine treated animals at this stage. By day 7, mucus secretion increased significantly $(P<0.05)$ in control, thyroidectomised and thyroxine treated rats respectively, but secretion was however lower $(P<0.05)$ in thyroidectomised rats than in control. By day 10 , mucus secretion was reduced in all groups of animals when compared with value on day 7. This fall was significant in control and thyroxine-treated, but not thyroidectomised rats (data shown in Table 3).

\section{Basal and Histamine Stimulated Gastric Acid Output}

By day 3, gastric acid secretion was $0.8 \pm 0.00 \mathrm{Meq} / \mathrm{L}$ in control animals. Basal secretion was significantly $(P<0.01)$ higher in thyroxine treated $(1.68 \pm 0.00 \mathrm{Meq} / \mathrm{L})$, and significantly reduced in thyroidectomised $(0.6 \pm 0.00 \mathrm{Meq} / \mathrm{L})(P<0.05)($ Table 4$)$ animals. As healing progressed on day 7 and 10, all groups of animals showed a significant decrease in basal gastric acid secretion $(P<0.05)$. Figure 3 shows that by day 7 , however, acid secretion significantly $(P<0.05)$ reduced in thyroidectomised and thyroxine treated rats, by $49.4 \pm$ $1.2 \%$ and $48.7 \pm 4.2 \%$ respectively, when compared with the reduction seen in controls $(34.7$ $\pm 2.2 \%$ ). By day 10 , gastric acid secretion was reduced by $65.0 \pm 0.0 \%$ in control animals, $77.4 \pm 2.6$ in thyroxine treated and $(51.5 \pm 3.3 \%)$ in thyroidectomised animals.

Thyroidectomy significantly $(P<0.05)$ reduced peak histamine stimulated gastric acid (PHSGA) $(1.69 \pm 0.05 \mathrm{Meq} / \mathrm{L})$ at day 3 post ulcer induction, while thyroxine treatment significantly $(P<0.001)$ increased PHSGA $(4.2 \pm 0.13 \mathrm{Meq} / \mathrm{L})$ at the same time point, when compared with control $(1.96 \pm 0.13 \mathrm{Meq} / \mathrm{L})$. By day 7 and 10, all groups of animals had a 
significant $(P<0.05)$ decrease in response to histamine (Table 5). However, at day 7 after ulcer induction, the percentage reduction in PHSGA was significantly $(P<0.01)$ higher in thyroxine treated animals $(36.6 \pm 5.2 \%)$ than in control $(17.9 \pm 8.0 \%)$ (Figure 4$)$. By day 10, the percentage decrease in PHSGA in thyroidectomised animals $(19.6 \pm 3.4 \%)$ was significantly $(P<0.05)$ less than in control $(30.4 \pm 1.9)$, while percentage reduction was significantly higher in thyroxine treated animals $(48.3 \pm 3.4 \%)(P<0.01)$ (Figure 4). 


\section{Discussion}

Gastric ulcer healing is a complex process that is influenced by several growth factors and hormones including; ghrelin, growth hormone, growth hormone-releasing factor, insulin-like growth factor-1 (IGF-1), progesterone and testosterone (Kontureket al. 1988b; Ceranowicz et al. 2009; Machowskaet al. 2004). Some of these hormones facilitate, while some delay healing. The results of our study further show that thyroxine treatment accelerates gastric ulcer healing by rapidly reducing the ulcer area compared to other groups and thyroidectomy delays healing, which is in line with previous reports (Olaleye et al. 2013; Adeniyi et al. (2014). This study is the first to also examine gastric acid secretion, mucus secretion and systemic inflammation by measuring neutrophil to lymphocyte ratio during healing in acetic acid induced ulcer that closely resembles human ulcer (Okabe and Amagase 2005).

The neutrophil-lymphocyte ratio is an indicator of inflammatory status and endotoxeamia (Halazunet al. 2008). During various stressful events, such as major surgery, burns, tissue injury, severe trauma and sepsis syndrome, the body immunity responds by increasing the number of circulating neutrophils and reducing lymphocyte counts. Elevated NLR is associated with higher level of inflammation, poor survival and increased morbidity in a number of diseases (Salciccioli et al. 2015), and with improvement of the clinical status in these conditions, there is gradual elevation in lymphocyte counts and concomitant reduction in neutrophil counts (reduced NLR) (Zahorec 2001). In our study, all groups except thyroidectomised rats showed a significant reduction in NLR by day 7 . This suggests that there is a rapid improvement of the ulcer condition in treatment groups other than the thyroidectomised, and therefore that thyroidectomy significantly slows healing rate. By day 10 however, all groups of animals had a significant decrease in NLR when compared with values in the same group at day 3; which indicates that some healing took place in all the 
animals. A look at the reduction in NLR revealed a greatest decrease in thyroxine treated animals when compared with control, while it was lowest in thyroidectomised animals (Figure 2). The higher reduction in NLR in thyroxine treated group indicates that healing and resolution of inflammation is faster in that group and contrary in thyroidectomised animals. Previous work found that NLR was higher in patients with peptic ulcer perforations and Helicobacter pylori infected ulcer than in control patients (Tanrikuluet al. 2015; Jafarzadeh et al. 2013), but there are no reports about the use of NLR to monitor the progress of ulcer healing. This research shows that the neutrophil lymphocyte ratio has the potential to be used to monitor progress of healing in acute gastric ulcer.

In this study, throxine treatment was done for 35 days before gastric ulcer was induced, then the first measurement of acid secretion was done by day 3 post ulcer induction, and result shows that both basal and histamine stimulated acid output was significantly higher in the thyroxine treated group as compared with control, while thyroidectomy significantly decreased gastric acid secretion. This increase in acid secretion in these treated rats could be due to an increase in parietal cell mass as previously reported by Adeniyi and Olowookorun (1989) and Rafsanjani et al. (2003). There are however contrary reports about the effects of thyroxine treatment on gastric acid secretion; Salami et al. (2016) and Dotevall et al. (1967) found out that thyroxine treatment decreased gastric acid secretion, although they could not fully explain how thyroxine treatment reduced acid secretion.

Furthermore, our study showed that gastric acid secretion reduced in all groups of rats by days 7 and 10 as healing progressed, and the highest percentage reduction in acid secretion was found in thyroxine treated rats, while the least reduction was found in thyroidectomised rats (Figure 3 and Figure 4). The is in line with the finding of Salami et al. (2016), who also 
discovered that acid secretion reduced in her animals during ulcer healing. This reduction might be a physiologic mechanism by which the body aids the healing of the wound. Clinically, reduction of gastric acid secretion is one of the main targets of physicians during ulcer treatment; with the aim to prevent progression of acute erosions into gastric ulcers, promote healing and prevent ulcer recurrence (Strand et al. 2017; Tuorkey and Abdul-Aziz, 2009; Tuorkey and Karolin, 2009; Brzozowski et al. 2000).

Data from Tables 4 and 5 show that the acid secretion in thyroxine treated rats (the group with most rapid healing) was higher than in control, thyroidectomised and thyroidectomy + T4 group. Acid is an aggressive factor that aggravates existing ulceration, therefore the faster healing observed in thyroxine treated rats cannot stem from this mechanism. Thus, the accelerated healing could be due to a topical effect of thyroxine on the wound, as many researchers have found accelerated healing when thyroxine was topically applied to wound (Safer et al. 2005; Kassem et al. 2012). The accelerated healing might also involve factors on the lining of the mucosa of the stomach, particularly relating to mucus secretion. This study further revealed that thyroxine treated rats responded to ulcer induction by secreting high volumes of mucus, comparable with that in control and higher than in thyroidectomised rats.

Previous researches have shown that adherent mucus secreted by the stomach both protects and accelerates the rate of healing (Oluwole and Saka 2007; Kobayashi et al. 2001; Adeniyi et al. 2016). The observation of significantly lower mucus secretion in thyroidectomised rats by days 3 and 7 (Table 3) may underlie delayed ulcer healing in these animals because the reduced mucus would be expected to expose the epithelial surface to more damaging effects of gastric $\mathrm{HCl}$, which will also interfere with re-epthelization (Leonard et al. 1994). On the other hand, the higher mucus secretion observed by days 3 and 7 in control, thyroxine treated 
and thyroxine replacement therapy might account for the faster healing seen in these groups. This agrees with the report of Oluwole and Saka (2007) that claimed that thyroxine treatment increases mucus secretion, and is also gastroprotective. Gastric mucus has also been found to act as antioxidant and create a suitable $\mathrm{pH}$ environment for the activities of growth factors to facilitate the processes of healing (Rowland et al. 2013; Yandrapu and Sarosiek 2015).

In conclusion, this study shows that during acute gastric ulcer, thyroxine facilitates healing by increasing mucus secretion, by modulating the body's immune system (reducing neutrophil lymphocyte ratio) and acid secretion.

\section{Disclosure}

No conflicts of interest, financial or otherwise, are declared by the authors. 


\section{References}

Adeniyi, K.O. and Olowookorun, M.O. 1989. Gastric acid secretion and parietal cell mass: Effect of thyroidectomy and thyroxine treatment. Am J Physiol. 256 (Gastroint. Liver Physiol.) G 975-978.

Adeniyi, O.S., Emikpe, B.E. and Olaleye, S.B. 2014. Gastric mucosa re-epithelisation, oxidative stress and apoptosis during healing of acetic acid induced ulceration in thyroxine treatment and thyroidectomy on rats. J Afr Ass Physiol Sci. 2 (1): 57 - 66.

Adeniyi, O.S., Omale, J., Egwuje,.RI.,Ajayi, O.S. 2016. Effect of Selenium Treatment on Healing of Acetic Acid Induced Gastric Ulcer in Albino Wistar rats. Am J Biomed Res. 4 (1): 18-22. doi: 10.12691/ajbr-4-1-4

Aihara, T., Nakamura, E., Amagase, K., Tomita, K., Fujishita, T., Furutani, K., et al. 2003. Pharmacological control of gastric acid secretion for the treatment of acid-related peptic disease: past, present, and future. Pharmacol Ther. 98 (1):109-27.

Allen, A. and Flemström, G. 2005. Gastroduodenal mucus bicarbonate barrier: protection against acid and pepsin. Am J Physiol Cell Physiol. 288 (1): 1-19. doi: 10.1152/ajpcell.00102.2004 
Brzozowski, T., Konturek, P.C., Konturek, S.J., Drozdowicz, D., Kwiecien, S., Pajdo, R. et al. 2000. Role of gastric acid secretion in progression of acute gastric erosions induced by ischemia-reperfusion into gastric ulcers. Eur J Pharmacol. 398: 147-158. doi.org/10.1016/S0014-2999(00)00287-9

Ceranowicz, P., Warzecha, Z., Dembinski, A., Sendur, R., Cieszkowski, J., Ceranowicz, D.et al. 2009. Treatment with ghrelin accelerates the healing of acetic acid-induced gastric and duodenal ulcers in rats. J Physiol Pharmacol. 60 (1): 87-98.

Corne, S.J., Morrissey, S.M., Woods, R.J. 1974. A method for the quantitative estimation of gastric barrier mucous. J Physiol. 242: 116P - 117P.

Dotevall, G., Rohrer, V., Stefco P., Price W. 1967.Relationship between gastric and thyroid function. Am J Dig Dis. 12(12): 1230 - 1239. doi: https://doi.org/10.1007/BF02233924

Ghosh, M.N. and Schild, H.O. 1958. Continuous recording of acid gastric secretion in the rat. Brit J Pharm.13: 54-61.

Halazun, K.J., Aldoori, A., Malik, H.Z., Al-Mukhtar, A., Prasad, K.R., Toogoo, G.J. et al. 2008. Elevated preoperative neutrophil to lymphocyte ratio predicts survival following hepatic resection for colorectal liver metastases. Eur J Surg Oncol. 34(1):55-60. doi: 10.1016/j.ejso.2007.02.014. 
Hu, Z., Huang, Y., Qin, B., Tang, Q., Yang, M., Ma, N. 2015. Prognostic value of neutrophil to lymphocyte ratio for gastric cancer. Ann Transl Med. 3(4): 50. doi: 10.3978/j.issn.23055839.2015.03.26.

Jafarzadeh, A., Akbarpoor, V., Nabizadeh, M., Nemati, M.Rezayati, M.T. 2013. Total leukocyte counts and neutrophil-lymphocyte count ratios among Helicobacter pylori-infected patients with peptic ulcers: independent of bacterial CagA status. Southeast Asian . Trop Med Public Health. 44(1): 82-88.

Kassem, R., Liberty, Z., Babaey, M., Trau, H., Cohen, O. (2012). Harnessing the skin-thyroid connection for wound healing: a prospective controlled trial in guinea pigs. Clin Exp Dematol. 37(8):850-6. doi: 10.1111/j.1365-2230.2012.04456.x. Epub 2012 Oct 22.

Khoder, G., Al-Menhali, A.A., Al-Yassir, F.Karam, S.M. 2016. Potential role of probiotics in the management of gastric ulcer. Exp Ther Med. 12(1): 3-17. doi: 10.3892/etm.2016.3293.

Kobayashi, T., Ohta, Y., Yoshino, J., Nakazawa, S. 2001. Teprenone promotes the healing of acetic acid-induced chronic gastric ulcers in rats by inhibiting neutrophil infiltration and lipid peroxidation in ulcerated gastric tissues. Pharmacol Res. 43(1):23-30.doi: 10.1006/phrs.2000.0748

Konturek, S.J., Dembinski, A., Warzecha, Z., Brzozowski, T., Gregory, H. 1988. Role of epidermal growth factor in healing of chronic gastroduodenal ulcers in rats. Gastroenterol; 94: $1300-1307$. 
Leonard, A., Droy-Lefaix, M.T., Allen, A. 1994. Pepsin hydrolysis of the adherent mucus barrier and subsequent gastric mucosal damage in rat: Effect of diosmectite and 16, 16dimethyl prostaglandin $\mathrm{E}_{2}$. Gastroenterol Clin Biol. 18: 609-616.

Lewis, S.M., Bain, B.J. Bates, I. 2006. Dacie and Lewis Practical Haematology. Tenth Edition. Churchill Livingstone. Elsevier LTD.

Ma, L. and Wallace, J.L. 2000. Endothelial nitric oxide synthase modulates gastric ulcer healing in rats. Am J Physiol.279:G341-G346.

Machowska, A., Szlachcic, A., Pawlik, M., Brzozowski, T., Konturek, S.J., Pawlik, W.W. 2004. The role of female and male sex hormones in the healing process of preexisting lingual and gastric ulcerations. J Physiol Pharmacol. 55(2): 91-104.

Nguyen, T., Chai, J., Li, A., Akahoshi, T., Tanigawa, T., Tarnawski, A.S. 2007. Novel Roles of Local Insulin-Like Growth Factor-1 Activation in Gastric Ulcer Healing: promotes actin polymerization, cell proliferation, re-epithelialization, and induces cyclooxygenase- 2 in a phosphatidylinositol 3-kinase-dependent manner. Am J Pathol. 170:1219-1228. doi: 10.2353/ajpath.2007.060745.

Okabe,.S and Amagase, K. 2005. An overview of acetic acid ulcer models - The history and state of the art of peptic ulcer research. Biol Pharm Bull.28(8): 1321-1341.

Olaleye, S.B., Adeniyi, O.S.Emikpe, B.O. 2013. Thyroxine Accelerates Healing of Acetic Acid-Induced Gastric Ulcer in Rats. Arch Bas App Med. 1:77 - 85. 
Olaleye, S.B., Ajeigbe, K.O., Emikpe, B.E. 2012. Effect of sulfadoxine-pyrimethamine and artesunate on gastric acid secretion and parietal cell mass in rats. Afr J Biomed Res. 15: 2328.

Oluwole, F.S. and Saka, M.T. 2007. Effect of Thyroid Hormone on Gastric Mucus Secretion Around Indomethacin Induced Gastric Ulcers in Rats. J Med Sci. 7: 678-681.doi: 10.3923/jms.2007.678.681.

Rafsanjani, F.N., Asl, S.Z., Naseri, M., Vahedian, J. 2003. Effects of thyroid hormones on basal and stimulated gastric acid secretion due to histamine, carbachol and pentagastrin in rats. Saudi Med J. 24 (4): 341-346.

Rowland, K.J., Choi, P.M., Warner, B.W. 2013.The role of growth factors in intestinal regeneration and repair in necrotizing enterocolitis. Semin Pediatr Surg. 22(2): 101-111.doi: 10.1053/j.sempedsurg.2013.01.007.

Safer, J.D., Crawford, T.M., Holick, M.F. 2005. Topical thyroid hormone accelerates wound healing in mice. Endocrinol. 146(10): 4425-30.

Salami, A.T., Odukanmi, O.A., Olagoke, C.O, Iyiola, T.O., Olaleye, S.B. 2016. Role of Nitric Oxide and Endogenous Antioxidants in Thyroxine Facilitated Healing of IschemiaReperfusion Induced Gastric Ulcers. Nig J Pharm Res. 12 (2):189-206 
Salciccioli, J.D., Marshall, D.C., Pimentel, M.A., Santos, M.D., Pollard, T., Celi, L.A. et al. 2015. The association between the neutrophil-to-lymphocyte ratio and mortality in critical illness: an observational cohort study. Crit Care. 19:13.

Soylu, K., Gedikli, O., Eksi, A., Avcioğlu, Y., Soylu, A.İ., Yüksel, S. et al. 2016. Neutrophilto-lymphocyte ratio for the assessment of hospital mortality in patients with acute pulmonary embolism. Arch Med Sci; 12(1): 95-100. doi: 10.5114/aoms.2016.57585

Strand, D.S., Kim, D., Peura, D.A. 2017.25 years of proton pump inhibitors: A comprehensive review. Gut Liver, 11(1): 27-37. doi: 10.5009/gnl15502.

Tanrikulu, Y., Sen Tanrikulu, C., Sabuncuoglu, M.Z., Kokturk, F., Temi, V., Bicakci, E. 2016. Is the neutrophil-to-lymphocyte ratio a potential diagnostic marker for peptic ulcer perforation? A retrospective cohort study. Am J Emerg Med. 34(3):403-6.doi: 10.1016/j.ajem.2015.11.009.

Tarnawski, A.S. and Ahluwalia, A. 2012. Molecular mechanisms of epithelial regeneration and neovascularization during healing of gastric and esophageal ulcers. Curr Med Chem. 19:16-27. doi: https://doi.org/10.2174/092986712803414088

Tuorkey, M..and Karolin, K. 2009. Anti-ulcer activity of curcumin on experimental gastric ulcer in rats and its effect on oxidative stress/antioxidant, IL-6 and enzyme activities. Biomed. Environ Sci.22, 488-495. doi: 10.1016/S0895-3988(10)60006-2. 
Tuorkey, M.J. and Abdul-Aziz, K.K. 2009. A pioneer study on the anti-ulcer activities of copper nicotinate complex [CuCl (HNA)2] in experimental gastric ulcer induced by aspirinpylorus [corrected] ligation model (Shay model). Biomed Pharmacother. 63, 194-201. doi: 10.1016/j.biopha.2008.01.015.

Wang, J.Y., Yamasaki, S., Takeuchi, K. Okabe, S. 1989. Delayed healing of acetic acidinduced gastric ulcers in rats by indomethacin. Gastroenterol. 96: 393-402.

Yandrapu, H. and Sarosiek, J. 2015. Protective Factors of the Gastric and Duodenal Mucosa: An Overview Cur Gastroenterol Rep. 17: 24. doi: 10.1007/s11894-015-0452-2

Zahorec R. 2001. Ratio of neutrophil to lymphocyte counts .rapid and simple parameter of systemic inflammation and stress in critically ill. Bratisl Lek Listy. 102 (1): 5-14. 


\section{Figures}

Figure 1: Percentage decrease in area of mucosa eroded in thyroxine treated and thyroidectomised animals after ulcer induction relative to Day 3.

$\mathrm{N}=5$, values are mean $\pm \mathrm{SEM}, *=$ significant compared with animals in control group on same day at $\mathrm{P}<0.05, \uparrow=$ significant when compared with thyroxine treated on same day at $\mathrm{P}$ $<0.05$.

Figure 2: Percentage decrease in neutrophil lymphocyte ratio after ulcer induction in thyroxine treated and thyroidectomised rats compared to day 3.

$\mathrm{N}=5$, value are mean $\pm \mathrm{SEM}, *=$ significant compared with animals in control group on same day at $\mathrm{P}<0.05$

Figure 3: Percentage reduction in basal acid secretion after ulcer induction in thyroxine treated and thyroidectomised rats compared to day 3.

$\mathrm{N}=5$, value are mean $\pm \mathrm{SEM}, *=$ significant compared with animals in control group on same day at $\mathrm{P}<0.05$

Figure 4: Percentage decrease in peak histamine stimulated gastric acid output after ulcer induction compared to day 3 .

$\mathrm{N}=5$, value are mean $\pm \mathrm{SEM}, *=$ significant compared with animals in control group on same day at $\mathrm{P}<0.05$ 
Table 1: Effect of thyroidectomy and thyroxine treatment on ulcer area during healing

\begin{tabular}{llll}
\hline Groups & \multicolumn{3}{c}{ Area $\left(\mathrm{mm}^{2}\right)$} \\
& Day 3 & Day 7 & Day 10 \\
\hline Control & $7.6 \pm 0.18$ & $3.1 \pm 0.29 \dagger$ & $2.1 \pm 0.06 \dagger \dagger$ \\
Thyroidetomised & $7.8 \pm 0.37 \dagger$ & $4.4 \pm 0.48 \dagger \dagger$ & $2.9 \pm 0.15^{*} \dagger \dagger$ \\
Thyroidectomised $+\mathrm{T} 4$ & $7.6 \pm 0.24 \dagger$ & $3.4 \pm 0.33 \dagger \dagger$ & $1.7 \pm 0.12 \dagger \dagger$ \\
Thyroxine treated & $5.4 \pm 0.24 *$ & $1.7 \pm 0.12 \ddagger$ & $1.2 \pm 0.06^{*} \ddagger$
\end{tabular}

$\overline{\text { Values presented as mean } \pm \mathrm{SEM}, \mathrm{N}=5, *=\text { significant compared with control on same day } 3}$ at $P<0.05, \ddagger=$ significant compared with value in same group on day 3 at $P<0.05, \dagger=$ significant, when value is compared with thyroxine treated on same day at $P<0.05$ 
Table 2: Effect of thyroidectomy and thyroxine treatment on neutrophil lymphocyte ratio after ulcer induction

\begin{tabular}{llll}
\hline Groups & Day 3 & Day 7 & Day 10 \\
\hline Control & $0.63 \pm 0.03$ & $0.50 \pm 0.03 \ddagger$ & $0.45 \pm 0.01 \dagger$ \\
Thyroidectomised & $0.75 \pm 0.03$ & $0.65 \pm 0.04 \dagger$ & $0.60 \pm 0.03^{*} \dagger \dagger$ \\
Thyroidectomised + T4 & $0.84 \pm 0.05^{*}$ & $0.55 \pm 0.05 \ddagger$ & $0.44 \pm 0.01 \dagger \ddagger$ \\
Thyroxine treated & $0.94 \pm 0.1^{*}$ & $0.45 \pm 0.01 \dagger$ & $0.33 \pm 0.04 * \dagger \dagger$ \\
\hline
\end{tabular}

$\overline{\text { Values presented as mean } \pm \mathrm{SEM}, \mathrm{N}=5, *=\text { significant compared with control on same day at }}$ $P<0.05, \dagger=$ significant, when value is compared with thyroxine treated on same day at $P<$ $0.05 \$=$ significant compared with animals in same group on day 3 at $P<0.05$ 
Table 3: Effect of thyroidectomy and thyroxine treatment on mucus secretion after ulcer induction

\begin{tabular}{llll}
\hline Groups & \multicolumn{2}{l}{ mg alcian blue/gm glandular tissue } & \\
& Day 3 & Day 7 & Day 10 \\
\hline Control & $2.6 \pm 0.10$ & $3.4 \pm 0.10 \ddagger$ & $1.3 \pm 0.2 \ddagger$ \\
Thyroidectomised & $1.9 \pm 0.18^{*}$ & $2.7 \pm 0.22 \ddagger^{*}$ & $2.3 \pm 0.35^{*}$ \\
Thyroidectomised $+\mathrm{T} 4$ & $2.8 \pm 0.12$ & $3.1 \pm 0.23$ & $2.0 \pm 0.15 \ddagger^{*}$ \\
Thyroxine treated & $2.3 \pm 0.15$ & $3.4 \pm 0.23 \ddagger$ & $2.1 \pm 0.30 \ddagger^{*}$
\end{tabular}

$\overline{\text { Values presented as Mean } \pm \mathrm{SEM}, \mathrm{N}=5,+=\text { significant compared with the previous day of }}$ measurement at $P<0.05, *=$ significant compared with value in control on same day at $P<$ 0.05 
Table 4: Effect of thyroidectomy and thyroxine treatment on basal gastric acid output after ulcer induction

\begin{tabular}{llll}
\hline Groups & \multicolumn{2}{c}{$\mathrm{Meq} / \mathrm{L}$} \\
& Day 3 & Day 7 & Day 10 \\
\hline Control & $0.80 \pm 0.00$ & $0.52 \pm 0.01 \ddagger$ & $0.28 \pm 0.0 \ddagger$ \\
Thyroidectomised & $0.60 \pm 0.00^{*}$ & $0.30 \pm 0.01 * \dagger$ & $0.28 \pm 0.0 \ddagger$ \\
Thyroidectomised $+\mathrm{T} 4$ & $0.98 \pm 0.00^{*}$ & $0.60 \pm 0.02 \ddagger$ & $0.30 \pm 0.01 \ddagger$ \\
Thyroxine treated & $1.68 \pm 0.00^{*}$ & $0.80 \pm 0.01 *+$ & $0.38 \pm 0.00 \ddagger$ \\
\hline
\end{tabular}

$\overline{\text { Value presented as mean } \pm \mathrm{SEM}, \mathrm{N}=5, *=\text { significant compared with control on same day at }}$ $P<0.05, \ddagger=$ significant compared with value in same group on day 3 at $P<0.05$ 
Table 5: Effect of thyroidectomy and thyroxine treatment on peak histamine-stimulated gastric acid output after ulcer induction

\begin{tabular}{llll}
\hline Groups & \multicolumn{3}{l}{ Meq/L } \\
& Day 3 & Day 7 & Day 10 \\
\hline Control & $1.96 \pm 0.13$ & $1.42 \pm 0.13 \ddagger$ & $1.36 \pm 0.0 \ddagger$ \\
Thyroidectomised & $1.69 \pm 0.05^{*}$ & $1.42 \pm 0.06 \ddagger$ & $1.34 \pm 0.09 \ddagger$ \\
Thyroidectomised $+\mathrm{T} 4$ & $2.10 \pm 0.12$ & $1.64 \pm 0.08 \ddagger$ & $1.48 \pm 0.11 \ddagger$ \\
Thyroxine treated & $4.2 \pm 0.13^{*}$ & $2.64 \pm 0.15^{*} \ddagger$ & $2.16 \pm 0.11^{*} \ddagger$ \\
\hline
\end{tabular}

$\overline{\text { Value presented as mean } \pm \mathrm{SEM}, \mathrm{N}=5, *=\text { significant compared with control on same day at }}$ $P<0.05, \ddagger=$ significant compared with value in same group on day 3 at $P<0.05$ 


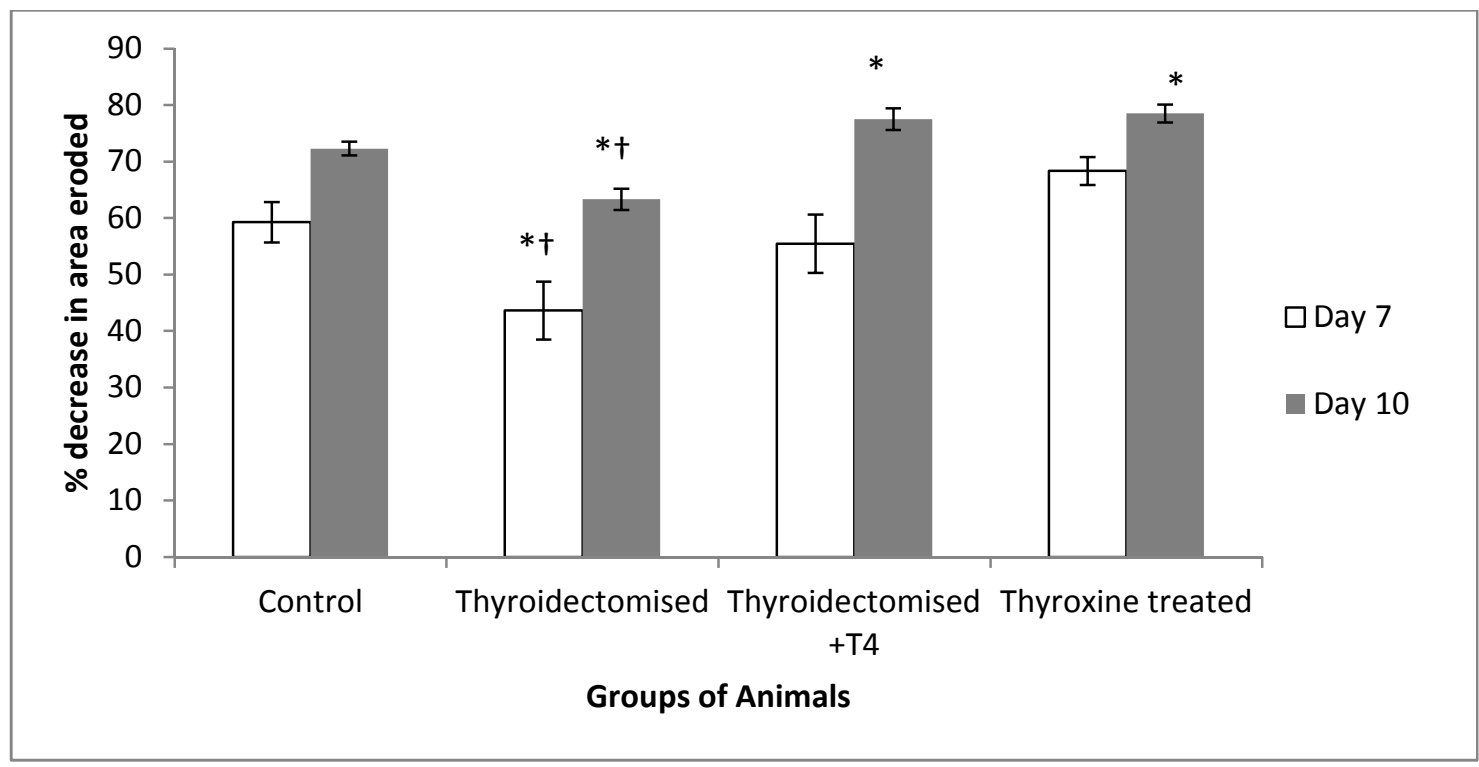

Figure 1: Percentage decrease in area of mucosa eroded in thyroxine treated and thyroidectomised animals after ulcer induction relative to Day 3.

$\mathrm{N}=5$, values are mean $\pm \mathrm{SEM}, *=$ significant compared with animals in control group on same day at $P<0.05, \dagger=$ significant when compared with thyroxine treated on same day at $P<0.05$. 


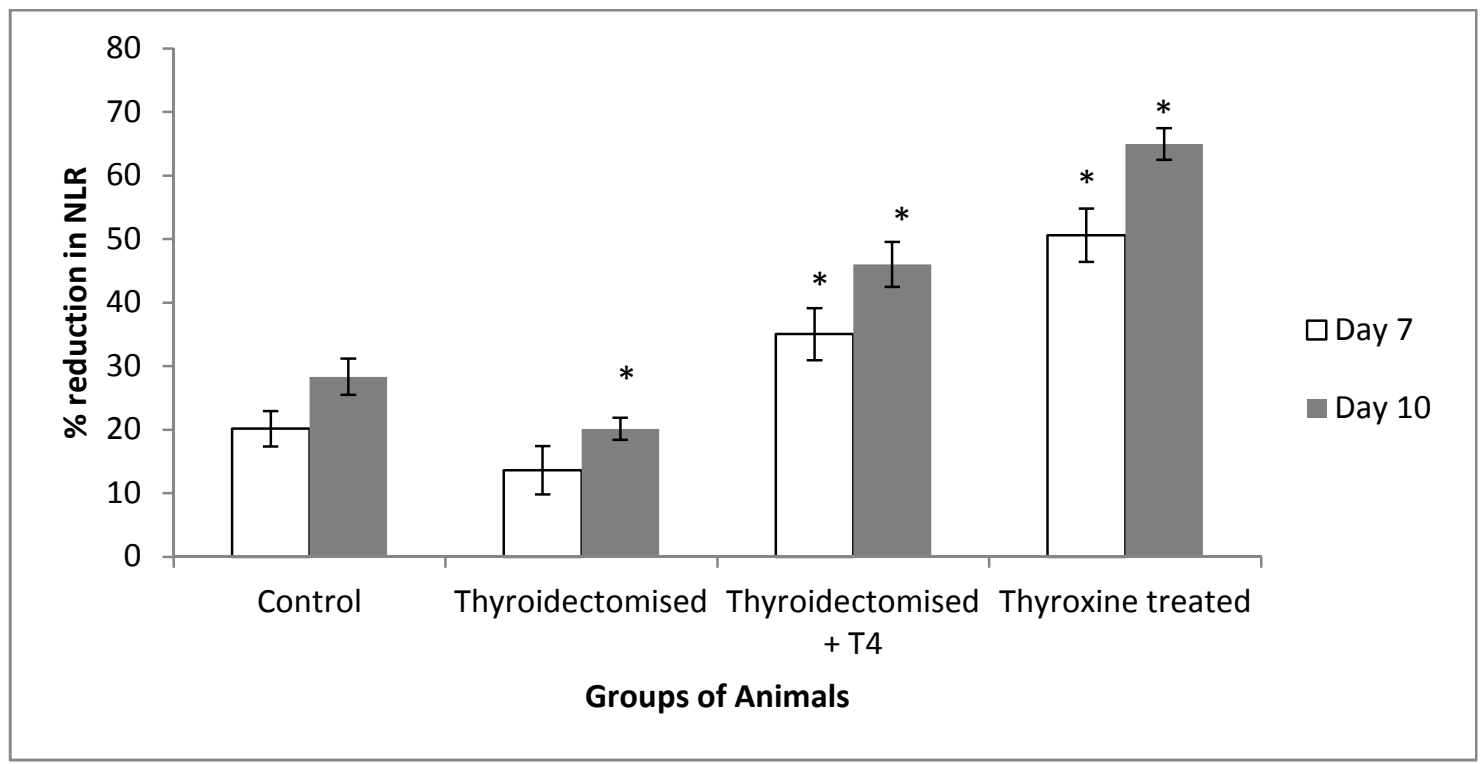

Figure 2: Percentage decrease in neutrophil lymphocyte ratio after ulcer induction in thyroxine treated and thyroidectomised rats compared to day 3 .

$\mathrm{N}=5$, value are mean $\pm \mathrm{SEM}, *=$ significant compared with animals in control group on same day at $P<0.05$ 


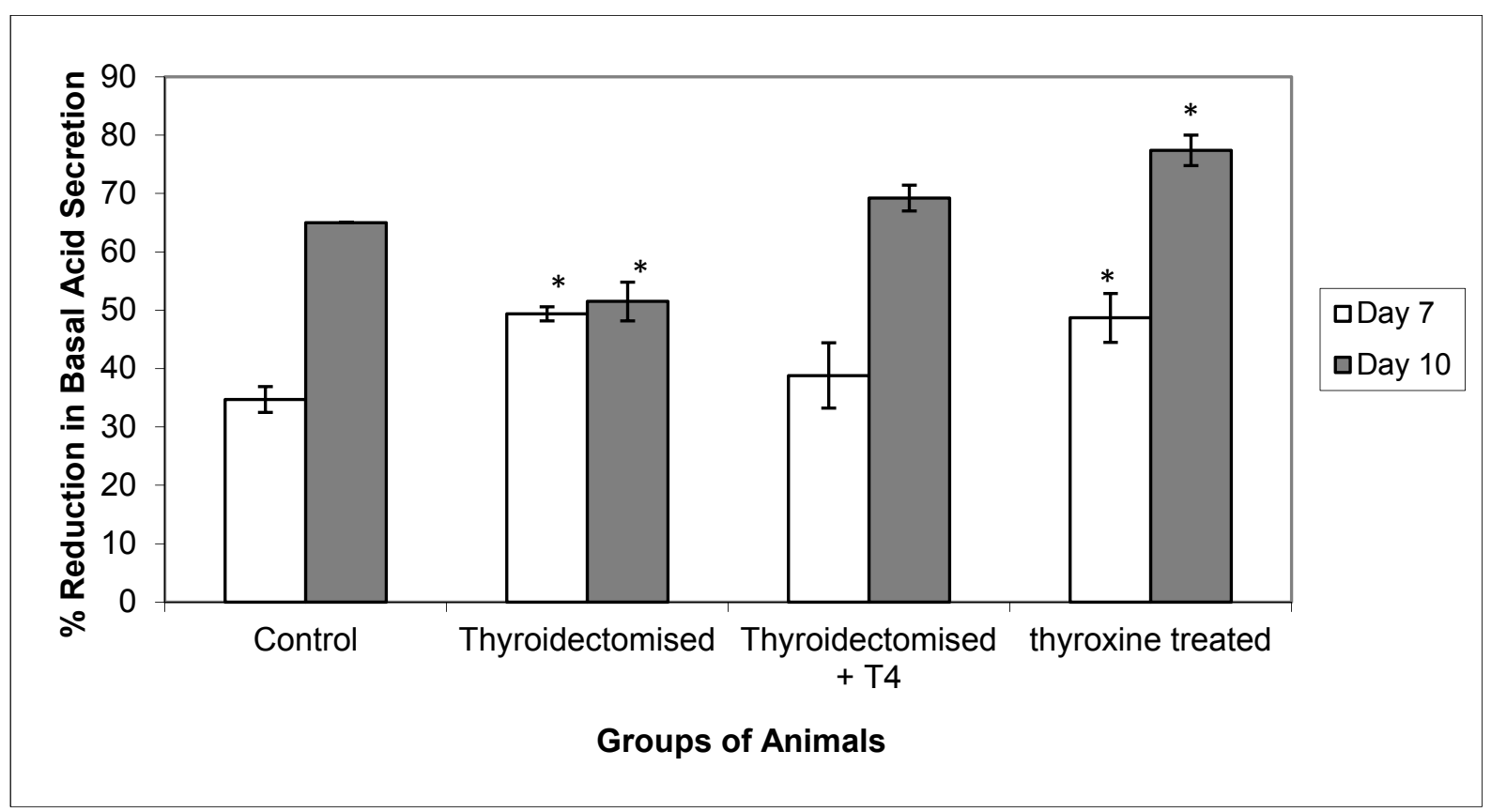

Figure 3: Percentage reduction in basal acid secretion after ulcer induction in thyroxine treated and thyroidectomised rats compared to day 3 .

$\mathrm{N}=5$, value are mean $\pm \mathrm{SEM}, *=$ significant compared with animals in control group on same day at $P<0.05$ 


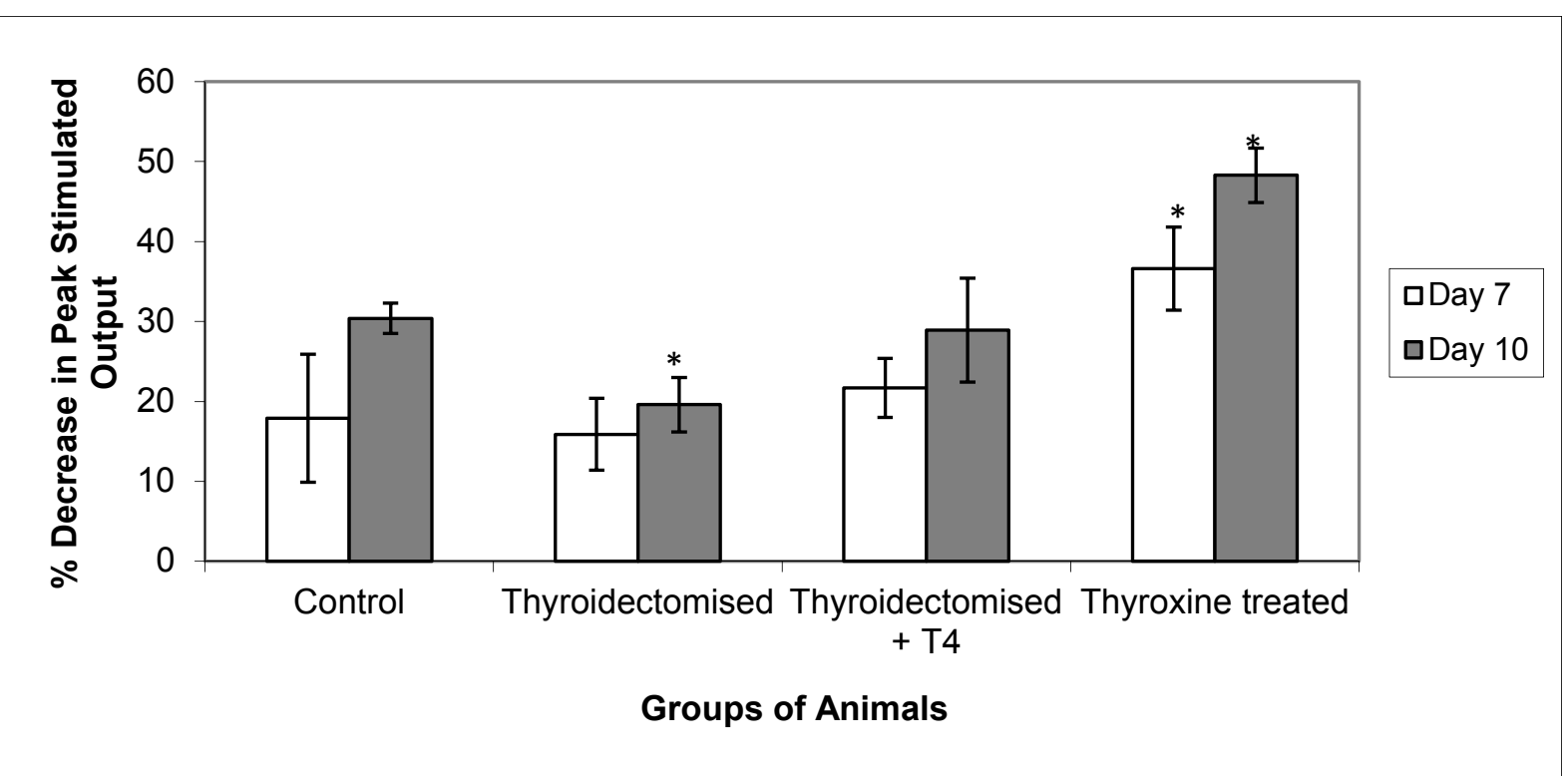

Figure 4: Percentage decrease in peak histamine stimulated gastric acid output after ulcer induction compared to day 3 .

$\mathrm{N}=5$, value are mean $\pm \mathrm{SEM}, *=$ significant compared with animals in control group on same day at $P<0.05$ 